\title{
Surgical treatment of vaginal vault prolapse
}

\author{
M.I.J. Withagen', R.M.F. van der Weiden', M.E. Vierhout' \\ 'Department of Obstetrics and Gynecology, \\ Radboud University Nijmegen Medical Centre, The Netherlands. \\ ${ }^{2}$ Department of Obstetrics and Gynecology, \\ Sint Franciscus Gasthuis, Rotterdam, The Netherlands
}

\begin{abstract}
Vaginal vault prolapse can cause limitations in physical and social functioning. This problem will enhance with the increasing age in women. New surgical techniques, like tension free vaginal mesh and laparoscopic sacrocolpopexy reduce surgical strain in patients and make prolapse surgery achievable in elderly women.
\end{abstract}

\section{Introduction}

Pelvic organ prolapse has a lifetime prevalence risk of $30 \%-50 \%$ and its incidence increases with age. ${ }^{1-3}$ The prevalence of pelvic organ prolapse in Nepal is quoted to be as high as $18-25.1 \%{ }^{4}$

The life-time risk of surgery for prolapse or incontinence by age 80 years is estimated to be $11.1 \%$ in the United States of America. ${ }^{5}$ The incidence of posthysterectomy vaginal vault prolapse is approximately $11.6 \%$ when assessed at surgery for prolapse and $1.8 \%$ when assessed at surgery for other benign diseases. ${ }^{6,7}$ These facts, coupled with an increased life expectancy, imply a considerable increase in the incidence of vault prolapse.

Although symptoms are not life threatening, women often have restrictions in physical, emotional and social functioning.

\section{Pathophysiology}

The position of the vagina in relation to the other structures in the pelvis prevents prolapse. The nulliparous vagina lies on the rectum and levator plate, with its axis directed to the hollow of the sacrum and its apex at or above the ischial spines (figure 1) ${ }^{8}$ This position provides support by the levator ani muscle against which the upper vagina is compressed by intraabdominal pressure (support). Previous surgery might change the position of the vagina resulting in loss of support. ${ }^{1}$

The vagina receives suspensory support from the pelvic sidewalls and the uterosacral cardinal ligament complex, formed by the condensation of the endopelvic fascia (suspension). This suspension can be weakened by direct and/or neuromuscular trauma following childbirth or by general pelvic connective tissue remodelling due to increased elastase or collagenase activity. ${ }^{9}$ Estrogen deficiency after menopause is thought to accelerate these processes but prevalence does not appear to be correlated with menopausal age. ${ }^{10}$ Risk factors for developing recurrent prolapse after previous prolapse surgery are: vaginal delivery in cases of fetal macrosomia ( $>4 \mathrm{~kg}$ ), a higher body mass index $(\mathrm{BMI}>30)$, women with advanced prolapse (POPQ-stage III or IV) and prolapse surgery in younger women $\left(<60\right.$ years). ${ }^{11,12}$

\section{Symptoms}

Post-hysterectomy vault prolapse frequently causes the typical sensation of prolapse ("something coming down", progression towards the end of the day), pelvic discomfort, low back pain, mucosal irritation, voiding difficulty, defecation disorders and sexual problems (1.Cutner).

\section{Correspondence}

Dr. M.I.J. Withagen, MD, UMC st Radboud

791, Secretariaat Obstetrie and Gynaecologie Postbox 9101, 6500 HB Nijmegen

Tel: 024-36147 92; Fax: 024-36685 97,E-mail:m.withagen@obgyn.umcn.nl 


\section{Diagnostic approach}

In the diagnostic approach we focus on pelvic examination. The extent of prolapse should be systematically assessed. The standard system for measurement, approved by the International Continence Society, consists of Pelvic Organ Prolapse Quantitation System (POP-Q) (13.Bump 1996). This system measures nine locations on the vagina and vulva in centimetres relative to the hymen. The use of vaginal speculums or retractors is very helpful in determining which vaginal sites are affected by prolapse.

Complementary imaging or testing seems only worthwhile for the diagnosis enterocele. Differentiation between rectocele and enterocele can be facilitated by defecography and dynamic MRI.

\section{Treatment}

Surgery is the most effective treatment for vaginal vault prolapse. Lack of support makes the use of pessaries difficult. There are different surgical techniques to treat vault prolapse: obliterative and non-obliterative procedures, vaginal and abdominal procedures, and minimally invasive percutaneous and laparoscopic techniques. In the last decades the use of mesh has been introduced in many of these treatment modalities.

\section{Vaginal obliterative procedures}

In elderly and medically high-risk women who are not sexually active vaginal vault prolapse can be treated effectively with (partial) vaginal closure or

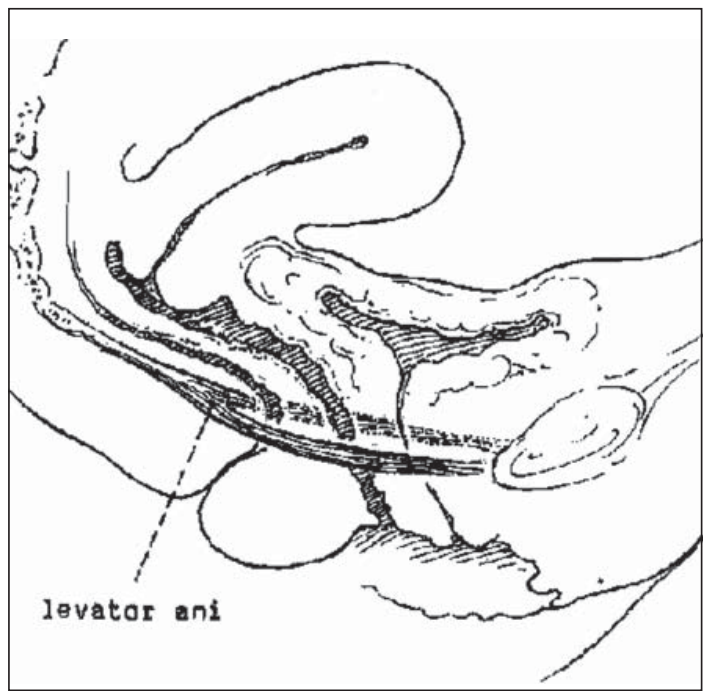

colpocleisis ${ }^{14}$. After removing vaginal mucosa from the anterior and posterior vaginal wall, the anterior wall is sutured to the posterior wall. Due to vaginal closure, intercourse is not possible anymore and $7-11 \%$ of the patients develop urinary incontinence. ${ }^{15}$ Success rates of $91-100 \%$ are reported.

An other partial obliterative procedure is the Labhardts high perineoplasty. ${ }^{16}$ This leaves only a minimal introitus. (figure 2)

\section{Vaginal procedures that suspend the apex}

Procedures for posthysterectomy vaginal vault prolapse anchor the vaginal apex to the available supporting tissue, including the sacrospinous ligaments, iliococcygeus or coccygeus fascia, uterosacral ligament, or sacrum.

The mostly used vaginal suspension technique is sacrospinous vaginal vault suspension according to Richter $^{17}$, mostly unilateral success rates of $69-92 \%$ are reported. ${ }^{18,19}$

Transvaginal fixation of the vault to the sacrospinous ligament restores the vaginal axis, but the technique can be fraught with difficulties. As the sutures are not inserted under direct vision haemorrhage may occur, caused by a laceration of the inferior gluteal artery, the pudendal vein and pudendal artery,the perirectal veins or the sacral veins. Injuries to the sciatic nerve, urinary tract, and rectum can also occur and the vagina may be shortened

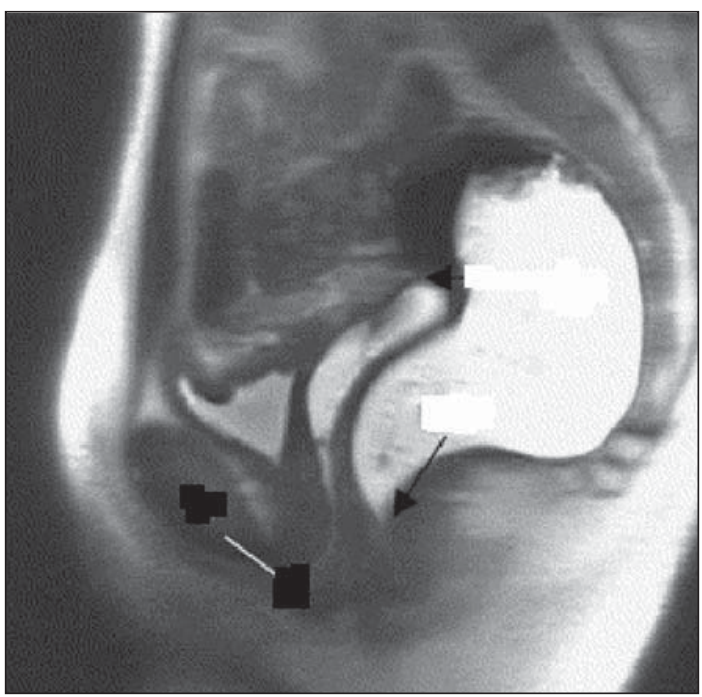

Figure I $\mathrm{a}+\mathrm{b}$ Nulliparous vagina, (of Vagina of a nullipara) its axis directed to the hollow of the sacrum and its apex at or above the ischial spines (almost horizontally)

a. Diagram

b. MRI 

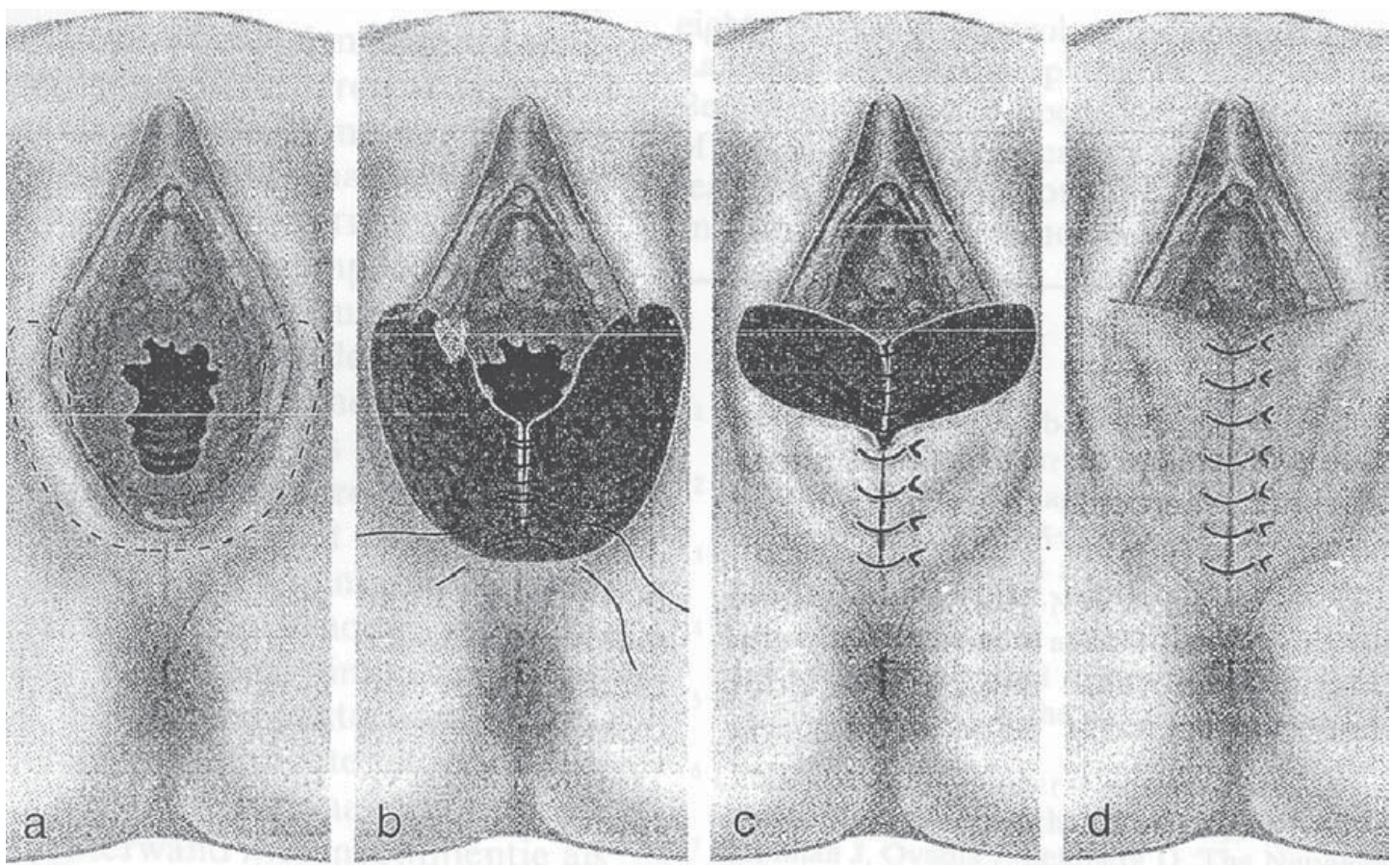

Figure 2. High perineoplasty according to Labhardt

\section{Vaginal procedures with mesh-material}

Based on conclusions from anatomical studies, Petros 20 developed the intravaginal slingplasty posterior (IVS posterior) or infracoccygeal sacropexy. IVS posterior is a minimally invasive transperineal approach. A narrow tunnelling device is used to pass a synthetic nonabsorbable tape through each pararectal space via a small perineal incision. A small vaginal incision is made to secure the tape to the vaginal vault. The objective was to reinforce vaginal support, by implanting a tension-free tape to create artificial uterosacral neoligaments. ${ }^{21}$ Recurrent prolapse is seen in $5.2-29 \%$. ${ }^{21-22}$ In an older population (21 women with an avarage age of 70 years) recurrent prolapse occurred in $63 \%$ within 18 months. ${ }^{23}$ High recurrence rate might be caused by the transmuscular fixation of a small tape $(8 \mathrm{~mm}) .{ }^{24}$ Furthermore it was shown in cadavers that IVS supports the midvagina, not the apex of the vagina. ${ }^{25}$ Complications of this procedure are perforation of the rectum, haemorrhage, erosion of the tape and dyspareunia. The multifilament polypropylene tape is associated with erosion and dyspareunia. ${ }^{26}$ Recently the multifilament tape is replaced by a monofilament tape.

The Tensionfree Vaginal Mesh (TVM) is another new minimal invasive technique. Instead of a tape, a large mesh is used to cover the entire posterior vaginal wall (and in other cases also the anterior vaginal wall. ${ }^{27}$. The mesh is monofilament polypropylene with arms to secure the mesh (figure 3 ). With this mesh posterior, middle and anterior compartment prolapse can be treated. The entire thickness of the posterior vaginal wall is dissected while keeping the rectovaginal fascia on the vaginal mucosa. The pararectal spaces are opened and dissection is performed until the sacrospinous ligament can be palpated. The posterior mesh has 2 arms that are placed in the middle part of the sacrospinous ligament, to suspend the apex of the vagina. If the vault prolapse is combined with an anterior prolapse, the mesh covering the anterior wall should be used. This type of mesh has 4 arms passing through the obturator foramen.

The first results are promising, with success rates for all types of prolapse was $80-95 \%$. 28-30 The following complications have been described: haemorrhage $(2 \%)$, bladder lesions $(0.9 \%)$, rectum lesions $(0.15 \%)$, perineal abscess $(0.15 \%)$, vesicovaginal fistula $(0.15 \%)$ and mesh erosion $(4.7-6.3 \%))^{29,30}$

\section{Abdominal procedures that suspend the apex}

In abdominal sacrocolpopexy the vaginal vault is attached to the sacrum. In the original description of this operation, the vault was attached directly to the sacrum ${ }^{31}$ Later, different materials were interposed between the vagina and sacrum with various technical modifications. The best known abdominal procedure is the sacrocolpopexy according to Rust ${ }^{32}$. This procedure involves placement of suture material into the ligamentous and periosteal fibrous connective 


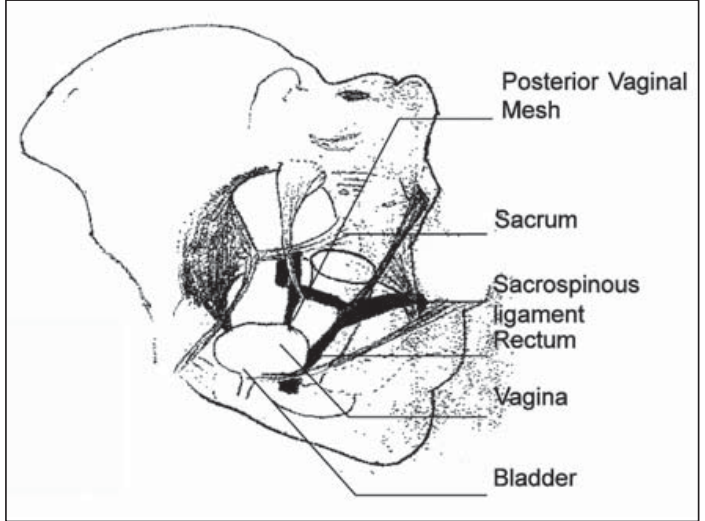

Figure 3a. Tensionfree vaginal mesh for posterior wall and vault

tissue in the midline of the anterior sacrum at the level of promontory or sacral segments 2-4. Haemorrhage from the presacral venous plexus $(4.4 \%)$ and damaging of the hypogastric nerve plexus are possible complications. ${ }^{33}$ Fixation to sacral segments $2-4$ is anatomically preferable, since fixation to the sacral promontory may result in a deviation of the vagina to an undesirable, almost vertical, axis, which can cause recurrent prolapse (figure 4). ${ }^{8}$ Stitches, tackers and bone anchors can be used to attach different kinds of mesh to the sacrum. Postoperative complications such as wound infection, ileus, sacral osteomyelitis and erosion of the mesh through the vagina are described. ${ }^{34}$ Erosion is associated with the type of mesh and with a combined vaginal-abdominal approach. Erosion can occur even years after surgery. ${ }^{35}$ Success rates of abdominal sacrocolopexy are $87-100 \%{ }^{36}$

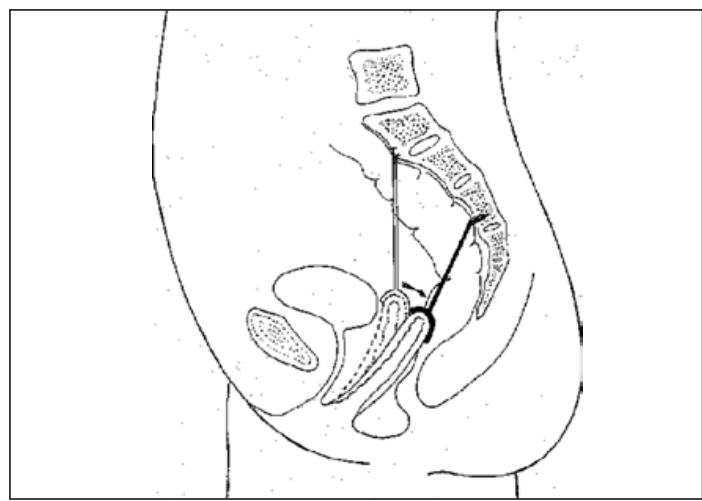

Figure 4. Fixation of mesh on sacral promontory results in an almost vertical vaginal axis. Fixation of mesh on sacral segment $\mathrm{S}_{3}$; the vagina lies on the rectum and levator plate (horizontal axis).

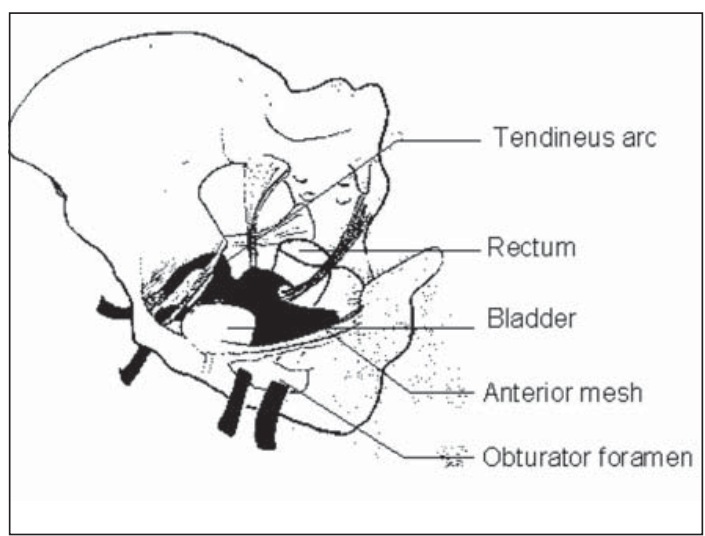

Figure 3b. Tensionfree vaginal mesh for anterior wall

\section{Laparoscopic procedures that suspend the apex}

In 1994, Nezhat decribed the first laparoscopic sacral colpopexy at the $\mathrm{S}_{3}-\mathrm{S}_{4}$ level ${ }^{37}$. Later reports describe a fixation of the mesh to the sacral promontory and mention results comparable to classical abdominal sacrocolpopexy. ${ }^{38,39}$ Fixation of the mesh to the sacral promontory is technically easier than fixation to $S_{3}$ or $\mathrm{S}_{4}$, but deviation of the vagina to an undesirable, almost vertical axis, enhances the risk of developing an enterocele. To facilitate the fixation to $\mathrm{S}_{3-4}$ a laparoscopic bone anchor inserter can be used (figure 5). ${ }^{40}$ This procedure requires even less dissection, which reduces the risk of injuries to the presacral venous and nervous plexus. Mesh related

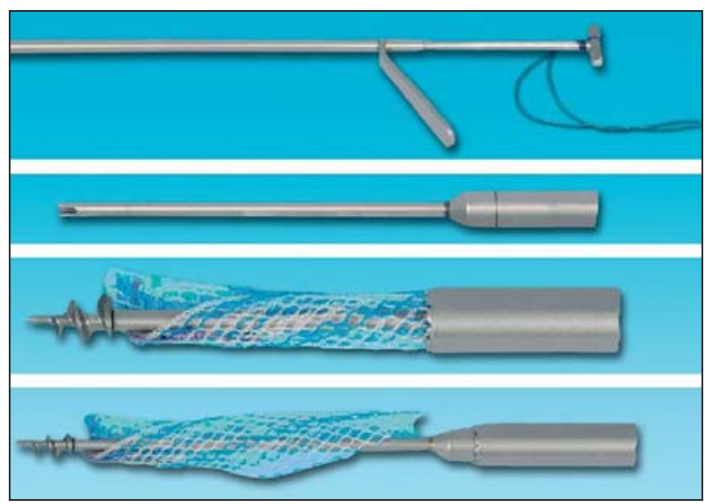

Figure 5. Laparoscopic bone anchor inserter (40. vd Weiden), existing of an inner and outer tube. This instrument attaches the mesh with a bone anchor to sacral segment 3 in one action.

a. inner tube inside outer tube

b. end of the inner tube

c. end of the inner and outer tube, bone anchor with mesh placed on inner tube

d. the same, inner tube further exposed 
complications are less likely to occur, since only a small amount of polypropylene mesh remains in a retroperitoneal position at the bottom of the pouch of Douglas.

Laparoscopic sacrocolpopexy has advantages over the open procedure, such as better visualization, access deep into the pelvis and a faster post-operative recovery. On the other hand it is a difficult technical procedure with al long learning curve.

\section{Conclusion}

With increasing life expectancy prolapse, and vault prolapse, will occur more often. Prolapse related symptoms cause restrictions in physical, emotional and social functioning. There is a whole range of possible surgical procedures to treat vault prolapse. In the past the elderly patient with comorbidity was not operated on due to increased operation risks. New effective surgical techniques as Tensionfree Vaginal Mesh and laparoscopic sacrocolpopexy are less invasive, safer and offer optimal treatment for the elder women.

\section{References}

1. Cutner AS, Elneil S. The vaginal vault. Br J Obstet Gynaecol 2004; 111 (Suppl 1): 79-83.

2. Samuelsson EC, Arne Victor FT, Tibblin G, Svardsudd KF. Signs of genital prolapse in a Swedish population of women 20 to 59 years of age and possible related factors. Am J Obstet Gynecol 1999; 180:299-305.

3. MacLennan AH, Taylor AW, Wilson DH, Wilson D. The prevalence of pelvic floor disorders and their relationship to gender, age, parity and mode of delivery. BJOG 2000; 107:1460-1470.

4. Tuladhar H. An overview of reproductive health of women in Bajhang district: Nepal Med Coll J 2005; 7(2):107-11

5. Olsen AL, Smith VJ, Bergstrom JO, et al. Epidemiology of surgically managed pelvic organ prolapse and urinary incontinence. Obstet Gynecol 1997;89:501-506.

6. Marchionni M, Bracco GL, Checcucci V et al. True incidence of vaginal vault prolapse. Thirteen year experience. J Reprod Med 1999; 44:679-684.

7. Barrington JW, Edwards G. Post hysterectomy vault prolapse. Int Urogynecol J Pelvic Floor Dysfunct 2000; 11:241-245.
8. Nichols DH, Milley PS, Randall CL. Significance of restoration of normal vaginal depth and axis. Obstet Gynecol 1970:251-256.

9. Mathrubutham M, Maytal A, Rao SK, et al. Elastolytic and collagenolytic activity is elevated in conditioned media from the skin and endopelvic fascia explants of women with pelvic floor weakening [abstact]. J Urol 2000; 163:95.

10. Versi E, Harvey MA, Cardozo L, Brincat M, Studd JW. Urogenital prolapse and atrophy at menopause: a prevalence study. Int Urogynecol J Pelvic Floor Dysfunct 2001; 12: 107-110.

11. Salvatore $\mathrm{S}$, Soligo $\mathrm{M}$, Athanasiou $\mathrm{S}$, et al. Identification and surgical implications of risk factors for recurrence of prolapse. 2005 Abstract 122 ICS Montreal.

12. Whiteside JL, Weber AM, Meyn LA, Walters MD. Risk factors for prolapse recurrence after vaginal repair. Am J Obstet Gynecol. 2004;191(5):1533-8.

13. Bump RC, Mattiasson A, Bo K, et al. The standardization of terminology of female pelvic organ prolapse and pelvic floor dysfunction. Am J Obstet Gynecol 1996; 175: 10-17.

14. Hanson GE, Keettel WC. The Neugebauer-Le Fort operation. A review of 288 colpocleises. Obstet Gynecol. 1969; 34(3):352-7.

15. FitzGerald MP, Richter HE, Siddique S, Thompson P, Zyczynski H. Colpocleisis: a review. Int Urogynecol J 2006;17:261-271.

16. Lammes FB. De behandeling van de genitale prolaps bij de hoogbejaarde vrouw. Ned Tijdschr Geneeskd 1997;141(45):2148-52.

17. Richter K. Die operative Behandlung des prolabierten Scheidengrundes nach Uterusextirpation. Beitrag zur Vaginaefixatio Sacrotuberalis nach Amreich. Geburtsh Frauenheilk 1967; 23: 941-954.

18. Sze EH, Karram MM. Transvaginal repair of vault prolapse: a review. Obstet Gynecol 1997; 89:466475.

19. Maher CF, Qatawneh AM, Dwyer PL, Carey MP, Cornish A, Schluter PJ. Abdominal sacral colpopexy or vaginal sacrospinous colpopexy for vaginal vault prolapse: a prospective randomized study. Am J Obstet Gynecol 2004; 190: 20-26. 
20. Petros PE. New ambulatory surgical methods using an anatomical classification of urinary dysfunction improve stress urge and abnormal emptying. Int Urogynecol J 1997;8:270-278.

21. Petros PE. Vault prolapse II: Restoration of dynamic vaginal supports by infracoccygeal sacropexy, an axial day-case vaginal procedure. Int Urogynecol J Pelvic Floor Dysfunct. 2001;12(5):296-303.

22. Jordaan DJ, Prollius A, Cronje HS, Nel M.Posterior intravaginal slingplasty for vaginal prolapse. Int Urogynecol J Pelvic Floor Dysfunct. 2006;17(4):326-9. Epub 2005 Sep 27

23. Mattox TF, Moore S, Stanford EJ, Mills BB. Posterior vaginal sling experience in elderly patients yields poor results. Am J Obstet Gynecol. 2006;194(5):1462-6. Epub 2006 Mar 31.

24. Boukerrou M, Lambaudie E, Collinet P, Rubod C, Boulanger L, Dubois $\mathrm{P}$, et al. Objective analysis of mechanical resistance of tension-free devices. Eur J Obstet Gynecol Reprod Biol. 2006 Feb 1;124(2):240-5. Epub 2005 Oct 5.

25. Jelovsek JE, Sokol, AI, Barber MD, Paraiso MFR, Walters MD. Anatomic relationships of infracoccygeal sacropexy (posterior intravaginal slingplasty) trocar insertion. Am J Obstet Gynecol 2005; 193: 2099-2104.

26. Baessler K, Hewson AD, Tunn R, Schuessler B, Maher CF. Severe mesh complications following intravaginal slingplasty. Obstet Gynecol 2005;106:713-716.

27. Berrocal JCH, Clavé H, Cosson M, Debodinance $\mathrm{P}$, Debodinance $\mathrm{Ph}$, Garbin $\mathrm{O}$, et al. Conceptual advances in the surgical management of genital prolapse. The TVM technique emergence. J Gynecol Obstet Biol Reprod 2004;33:377-87.

28. Cosson M, Caquant F, Collinet P, Rosenthal C, Clave H, Debodinance P, et al. Prolift (Mesh gynecare) for pelvic organ prolapse surgical treatment using the TVM group technique: a retrospective study of 687 patients. 2005 Abstract 121 ICS Montreal 2005

29. de Tayrac R, Devoldere G, Renaudie J, villard P, Guilbaud O, Eglin G. Prolapse repair by vaginal route using a new protected low-weight polypropylene mesh: 1 year functional and anatomical outcome in a prospective multicentre study. Int Urogynecol J Pelvic Floor Dysfunct 2006; [epub ahead of print]
30. Fatton B, Amblard J. Dobodinance P, Cosson M, Jacquetin B. Transvaginal repair of genital prolapse: preliminary results of a new tensionfree vaginal mesh (Prolift technique)-a case series multicentric study. Int Urogynecol J Pelvic Floor Dysfunct. 2007 Jul;18(7):743-52. Epub 2006 Nov 28.

31. Falk HC. Uterine prolapse and prolapse of the vaginal vault treated by sarcocolpopexy. Obstet Gynecol 1961;18:113-115.

32. Rust J, Botte J, Howlett R. Prolapse of the vaginal vault. Improved techniques for management of the abdominal approach or vaginal approach. Am J Obstet Gynecol 1976; 125: 768-776.

33. Maas CP, De Ruiter MC, Kenter GG, Trimbos JB. The inferior hypogastric plexus in gynaecological surgery. J Gynecol Tech 1999;5: 55-62.

34. Timmons MC. Tansabdominal sacral colpopexy. Oper Tech Gynecol Surg 1996;1:92-6.

35. MattoxTF, Stanford EJ, Varner E. Infected abdominal sacrocolpopexies: diagnosis and treatment. Int Urogynecol J Pelvic Floor Dysfunct. 2004 15(5):319-23. Epub 2004 May 14.

36. Nygaard IE, McCreery R, Brubaker L, Connolly AM, Cundiff G, Weber AM et al. Abdominal Sacrocolpopexy: A Comprehensive Review. Obstet Gynecol 2004;104:805-823

37. Nezhat CH, Nezhat F, Nezhat C. Laparoscopic sacral colpopexy for vaginal vault prolapse. Obstet Gynecol 1994;84: 885-888.

38. Cosson M, Rajabally R, Bogaert E, Querleu D, Crepin G. Laparoscopic sacrocolpopexy, hysterectomy, and Burch colposuspension: feasibility and short-term complications of procedures. JSLS 2002;6: 115-119.

39. Gadonneix P, Ercoli A, Salet-Lizée D, Cotelle O, Bolner B, Van Den Akker M, Villet R. Laparoscopic sacrocolpopexy with two separate meshes along the anterior and posterior vaginal walls for multicompartment pelvic organ prolapse. J Am Assoc Gynecol Laparosc 2004; 11: 29-35.

40. Van der Weiden RMF, Withagen MIJ, Bergkamp ABM, Mannaerts GGH. A new device for bone anchor fixation in laparoscopic sacrocolpopexy: the Franciscan laparoscopic bone anchor inserter. Surg Endosc 2005; 19: 594-597. 